\title{
LUNG TRANSPLANTATION IN VERY YOUNG INFANTS
}

Charles B. Huddleston, MDa

Stuart C. Sweet, $\mathrm{MD}^{\mathrm{b}}$

George B. Mallory, $\mathrm{MD}^{\mathrm{b}}$

Aaron Hamvas, $\mathrm{MD}^{\mathrm{c}}$

Eric N. Mendeloff, MD
Introduction: Established successes with adult lung transplantation have laid the foundation for extension of this therapeutic modality to infants and children dying of end-stage pulmonary disease. The purpose of this report is to convey our experience with 19 infants undergoing lung transplantation before the age of 6 months. Methods: Six patients with predominantly pulmonary vascular disease and 13 patients with primarily pulmonary parenchymal disease have undergone bilateral sequential lung transplantation at our institution since 1990. Mean age at transplant was $104 \pm 44$ days, and mean weight was $4.9 \pm 1.6 \mathrm{~kg}$. Results: Although early mortality $(32 \%, 6 / 19)$ was higher than that previously reported for older pediatric age groups, long-term survival was similar (44\% at a maximum follow-up of 6 years). Although anastomotic complications and infections occurred at a rate approximating that seen in older pediatric age groups, episodes of acute rejection appear to occur with decreased frequency. Similarly, at a mean follow-up of 3 years, only 2 (15\%) of 13 long-term survivors have evidence of bronchiolitis obliterans. The functional residual capacity, as measured on infant pulmonary function tests, has gradually increased as the children have grown, suggesting that lung growth is occurring. Conclusions: Bilateral lung transplantation is a viable alternative in infants dying of end-stage pulmonary disease. Efforts directed toward avoiding the complications that lead to early posttransplant mortality combined with the seemingly lower incidence of early and late rejection may provide long-term results better than those in other age groups. ( $J$ Thorac Cardiovasc Surg 1999;118:796-804)
$\mathrm{P}$ ediatric lung transplantation in many ways grew out of the successes seen with this treatment modality in adults. Clearly there has been a need for this because significant numbers of children die from end-stage pulmonary parenchymal and pulmonary vascular disease each year. The extension of lung transplantation to younger age groups seems the next most logical step in this evolution. There are important unknown issues peculiar to infant lung transplant recipients, including

From the Division of Cardiothoracic Surgery, ${ }^{a}$ Division of Pediatric Allergy/Pulmonary Medicine, ${ }^{\mathrm{b}}$ and the Division of Neonatology, ${ }^{\mathrm{c}}$ Washington University School of Medicine, St Louis Children's Hospital, St Louis, Mo.

Read at the Seventy-ninth Annual Meeting of The American Association for Thoracic Surgery, New Orleans, La, April 18-21, 1999.

Received for publication April 22, 1999; revisions requested July 12, 1999; revisions received July 30, 1999; accepted for publication Aug 2, 1999.

Address for reprints: Charles B. Huddleston, MD, \#1 Children's Place, Suite 5S 50, Children's Hospital, St. Louis, MO 63110.

Copyright (C) 1999 by Mosby, Inc.

$0022-5223 / 99 \$ 8.00+0 \quad \mathbf{1 2 / 6 / 1 0 1 9 2 1}$ whether there is growth of the transplanted organs, the feasibility of surveillance biopsies in small infants, technical aspects of the transplant operation itself, and the ever-present issue of donor availability. Nonetheless, there are infants who are otherwise completely normal but have lethal lung diseases developing soon after birth. We previously reported our results in lung transplantation for children less than 2 years of age in 1996. ${ }^{1}$ Taking this a step further, we reviewed our experience with lung transplantation in very young infantsthose less than 6 months of age at the time of transplantation-to assess their survival and general quality of life. This review includes 4 of the patients described in our previously published article. ${ }^{1}$

\section{Methods}

Patients. Since 1990, 180 lung transplants have been performed on children at St Louis Children's Hospital. During this time, 26 infants less than 5 months of age were evaluated and listed for lung transplantation. Seven died while awaiting transplantation, and 19 went on to undergo successful trans- 
Table I. Clinical summary of all infants referred for lung transplantation

\begin{tabular}{|c|c|c|c|c|c|c|c|}
\hline $\begin{array}{l}\text { Patient } \\
\text { No. }\end{array}$ & Diagnosis & $\begin{array}{l}\text { Age at } \\
\text { Listing }\end{array}$ & $\begin{array}{l}\text { Pretransplant } \\
\text { course }\end{array}$ & $\begin{array}{c}\text { Age at } \\
\text { transplant }\end{array}$ & Outcome & Follow-up & Cause of death \\
\hline 1 & SPB def & $16 \mathrm{~d}$ & ECMO then HFOV & $70 \mathrm{~d}$ & Retransplant for ARDS, A \& W & $5.2 \mathrm{y}$ & \\
\hline 2 & SPB def & $9 \mathrm{~d}$ & ECMO then HFOV & $59 \mathrm{~d}$ & $A \& W$ & $5.1 \mathrm{y}$ & \\
\hline 3 & SPB def & $29 \mathrm{~d}$ & HFOV & $72 \mathrm{~d}$ & Died $42 \mathrm{~d}$ after transplant & & Adenovirus infection \\
\hline 4 & SPB def & $29 d$ & HFOV & $144 \mathrm{~d}$ & A \& W & $1.34 \mathrm{y}$ & \\
\hline 5 & SPB def & $49 \mathrm{~d}$ & CPR, ECMO, HFOV & $78 \mathrm{~d}$ & Died $38 \mathrm{~d}$ after transplant & & Hepatic failure \\
\hline 6 & SPB def & $88 \mathrm{~d}$ & Tachypnea & $119 \mathrm{~d}$ & A \& W & $3 \mathrm{mo}$ & \\
\hline 7 & PAP & $43 \mathrm{~d}$ & HFOV & $65 \mathrm{~d}$ & A \& W & $3.9 \mathrm{y}$ & \\
\hline 8 & PAP & $31 \mathrm{~d}$ & ECMO, HFOV & $62 \mathrm{~d}$ & Died 9 mo after transplant & & Unknown \\
\hline 9 & PAP & $148 \mathrm{~d}$ & Standard vent & $158 \mathrm{~d}$ & Died 1.9 y after transplant & & $\mathrm{OB}$ \\
\hline 10 & PAP & $69 \mathrm{~d}$ & HFOV & $165 \mathrm{~d}$ & A \& W & $1.1 \mathrm{y}$ & \\
\hline 11 & CIP & $157 \mathrm{~d}$ & Standard vent & $192 \mathrm{~d}$ & Died $67 \mathrm{~d}$ after transplant & & Hepatic failure \\
\hline 12 & CIP & $63 \mathrm{~d}$ & ECMO, HFOV, pnx's & $107 \mathrm{~d}$ & $\mathrm{~A} \& \mathrm{~W}$ & $1.4 \mathrm{y}$ & \\
\hline 13 & CIP & $130 \mathrm{~d}$ & HFOV & $132 \mathrm{~d}$ & Died 2.2 y after transplant & & OB \\
\hline 14 & TOF, Phtn & $110 \mathrm{~d}$ & ECMO & $116 \mathrm{~d}$ & Died $16 \mathrm{~d}$ after transplant & & Graft failure \\
\hline 15 & $\mathrm{CDH}$ & $25 \mathrm{~d}$ & ECMO, NO, HFOV & $36 \mathrm{~d}$ & Died 14 days after transplant & & MSOF \\
\hline 16 & PVS & $79 \mathrm{~d}$ & Standard vent & $83 \mathrm{~d}$ & $A \& W$ & $6 y$ & \\
\hline 17 & PVS & $69 \mathrm{~d}$ & ECMO & $95 \mathrm{~d}$ & A \& W & $4.7 \mathrm{y}$ & \\
\hline 18 & PVS & $129 \mathrm{~d}$ & Standard vent & $133 \mathrm{~d}$ & Died $9 \mathrm{~d}$ after transplant & & Graft failure \\
\hline 19 & Phtn & $119 \mathrm{~d}$ & ECMO & $139 \mathrm{~d}$ & $\mathrm{~A} \& \mathrm{~W}$ & $0.5 \mathrm{y}$ & \\
\hline 20 & SPB def & $21 \mathrm{~d}$ & ECMO, HFOV & & Died $33 \mathrm{~d}$ after listing & & CNS bleed \\
\hline 21 & $\mathrm{ACD}$ & $15 \mathrm{~d}$ & ECMO & & Died $4 \mathrm{~d}$ after listing & & CNS bleed \\
\hline 22 & $\mathrm{ACD}$ & $20 \mathrm{~d}$ & NO, ECMO & & Died $23 \mathrm{~d}$ after listing & & MSOF \\
\hline 23 & PVS & $169 \mathrm{~d}$ & & & Died $34 \mathrm{~d}$ after listing & & Pulmonary bleed \\
\hline 24 & $\mathrm{Phtn} / \mathrm{rCHD}$ & $105 \mathrm{~d}$ & Prostacyclin, standard vent & & Died $22 \mathrm{~d}$ after listing & & Pulmonary bleed \\
\hline 25 & $\mathrm{Phtn} / \mathrm{rCHD}$ & $91 \mathrm{~d}$ & ECMO & & Died $13 \mathrm{~d}$ after listing & & MSOF \\
\hline 26 & Phtn & $8 \mathrm{~d}$ & ECMO, HFOV, NO & & Died $30 \mathrm{~d}$ after listing & & MSOF \\
\hline
\end{tabular}

$S P B$ def, Surfactant protein B deficiency; $E C M O$, extracorporeal membrane oxygenation; $H F O V$, high-frequency oscillating ventilator; $A R D S$, adult respiratory distress syndrome; $A \& W$, alive and well; $C P R$, cardiopulmonary resuscitation; $P A P$, pulmonary alveolar proteinosis; $O B$, bronchiolitis obliterans; $C I P$, congenital interstitial pneumonitis; pnx's. pneumothoraces; TOF, tetralogy of Fallot; Phtn, pulmonary hypertension; $C D H$, congenital diaphragmatic hernia; $M S O F$, multisystem organ failure; PVS, pulmonary vein stenosis; $C N S$, central nervous system; $A C D$, alveolar-capillary dysplasia; $r C H D$, repaired congenital heart disease.

plantation before the age of 6 months. This group forms the basis for this report. The details of the diagnosis and course of the entire group is depicted in Table I. The average age at listing was $67 \pm 51$ days, and the average age at the time of transplantation was $104 \pm 44$ days. The average weight at the time of transplantation was $4.9 \pm 1.6 \mathrm{~kg}$. The waiting time from listing to transplantation was $34 \pm 31$ days. The waiting time for the years 1993 to 1995 was $26 \pm 20$ days, and that for the period from 1996 to 1998 was $40 \pm 31$ days; this was not a statistically significant difference $(P=.36)$.

Pretransplant diagnosis. A variety of diagnoses were seen in this group of patients. In general, they can be described as infants born at term demonstrating respiratory distress since birth. Seven had surfactant protein-B deficiency, 4 had pulmonary alveolar proteinosis of other etiology, 3 had congenital interstitial pneumonitis, 2 had alveolar-capillary dysplasia, and 10 had pulmonary vascular disease. Of those with pulmonary vascular disease, the most common diagnosis was congenital pulmonary vein stenosis occurring in 4 . Four of the 10 with pulmonary vascular disease and 3 of the 15 with pulmonary parenchymal disease died while awaiting transplantation. Both infants with alveolar-capillary dysplasia died while awaiting transplantation.
Pretransplant evaluation. All other organ systems were evaluated to assess viability before listing. Evidence of serious, irreversible injury to any other organs excluded the infant from listing. In addition, investigation of the social circumstances, including a frank discussion with the parents regarding the commitment and uncertainties involved in this therapy, took place before transfer to our institution. Mechanical ventilation was not used as a contraindication to transplantation; on the contrary, all but one of these infants were ventilated at the time of referral. Perhaps the major issue addressed pertaining to the consideration for transplantation was whether there was any reasonable chance of reversibility of the lung disease. Listing for transplantation was done only when we were certain that the pulmonary process was irreversible.

Transplant technique. The transplant procedure was performed just as we do with our older children. The approach was through a bilateral anterolateral transsternal (clamshell) thoracotomy incision. Cardiopulmonary bypass was used in all instances. The bilateral sequential lung transplant technique was used, and bronchial anastomoses were wrapped with donor and recipient peribronchial tissue. A Broviac catheter was placed in all patients for chronic vascular access. 
Immunosuppression and surveillance. Triple drug (cyclosporine [INN: ciclosporin], azathioprine, steroids) immunosuppression was used. Target trough cyclosporine levels were 300 to $400 \mathrm{ng} / \mathrm{mL}$ for the first year after transplantation and 200 to $250 \mathrm{ng} / \mathrm{mL}$ thereafter. Infant pulmonary function tests were performed every 3 months for the first 2 years and every 6 months thereafter. Surveillance bronchoscopy was performed at regular intervals after transplantation: at 2 weeks, 1 month, 2 months, 3 months, and every 3 months thereafter. Transbronchial biopsies were performed at these intervals and at any time that a change in clinical status occurred in which rejection was a plausible explanation. The technique of transbronchial biopsy performed in these small infants has been described. ${ }^{2}$ When tissue sampling was inadequate and a change in clinical status persisted, open lung biopsy was performed.

Infant pulmonary function tests were performed at the same intervals as for bronchoscopy. Measurement of functional residual capacity (FRC) was made through an opencircuit nitrogen-washout technique (Sensormedics Corporation, Yorba Linda, Calif). ${ }^{3}$ After FRC measurements, rapid thoracoabdominal compressions were performed to obtain partial expiratory flow volume curves, and flow at FRC was recorded. ${ }^{4}$ Flow measurements were obtained by means of a pneumotachometer, and the flow signal was integrated to yield volume. Compressions were accomplished with the Hugger Cart 2605 (Equilibrated Bio Systems, Inc, Melville, NY). Criteria for acceptance of expiratory flow volume curves were as follows: rapid expulsion of expiratory flow with peak flow occurring before the midpoint of expiratory time, smooth expiratory curve without significant flow transients, and expiration beyond FRC. ${ }^{5}$

Statistics. Values expressed are means \pm standard deviations. Survival was calculated by using the Kaplan-Meier technique.

\section{Results}

Deaths while awaiting transplantation. As mentioned above, 7 patients died while awaiting transplantation. Four (40\%) of the 10 infants with some form of pulmonary hypertension and $3(19 \%)$ of 16 with pulmonary parenchymal diseases died. These deaths occurred at an average of $23 \pm 11$ days after listing. The causes of death generally reflected complications of intensive care unit (ICU) care: central nervous system bleed while receiving extracorporeal membrane oxygenation (ECMO), sepsis, and renal failure in combination with other organ system failure.

Pretransplant therapy. The average waiting time for donor organs for those infants undergoing transplantation was $34 \pm 32$ days. Because most are quite ill by the time of referral, it is paramount that a stable means of therapy be possible. All of these infants except one were receiving mechanical ventilation before transplantation. The one infant who was not had a genetic diagnosis of a variant of surfactant protein $B$ deficiency and was receiving escalating amounts of supplemental oxygen. At some point in their pretransplant course, 9 infants were receiving ECMO, although only 2 underwent transplantation while still receiving ECMO. These 2 infants were unable to be weaned from ECMO in spite of maximal medical therapy; one had congenital pulmonary venous stenosis, and the other had pulmonary hypertension related to a congenital diaphragmatic hernia. For those with pulmonary parenchymal disease, a high-frequency oscillating ventilator was used effectively to provide stable respiratory status. Pulmonary hypertension was managed with a combination of nitric oxide, prostacyclin, and inotropic agents.

Transplant data. All transplants were bilateral and whole lung except for 2 infants who received lower lobes only from significantly bigger donors. Many of the recipients required volume reduction of the lungs to properly fit into the chest. The average age at the time of lung transplantation was $104 \pm 44$ days (range, 36 to 192 days), and the average weight was $4.9 \pm 1.6 \mathrm{~kg}$ (range, 3.2 to $7.2 \mathrm{~kg}$ ); the average donor weight was 6.9 $\pm 2.9 \mathrm{~kg}$. The average time on cardiopulmonary bypass was $175 \pm 56$ minutes. The ischemic time to the first lung implanted was $228 \pm 77$ minutes, whereas that to the second lung implanted was $278 \pm 81$ minutes. Those surviving this hospitalization were ventilated for $24 \pm 19$ days and spent $56 \pm 33$ days in the hospital after the transplant procedure. Thus the total length of hospitalization (before and after transplantation) at our institution alone was approximately 3 months, most of which was in an ICU.

\section{Early posttransplant complications}

Anastomotic complications. Two patients required reoperation for left pulmonary artery occlusion early after transplantation. In both cases this was noted, with the perfusion scan done within 4 hours of arrival in the ICU after transplantation. Varying degrees of malacia of the native airway were noted in 4 patients, one of whom ultimately was treated with an airway stent; the other 3 had gradual resolution of the malacia, although one required tracheostomy. Anastomotic airway stricture occurred in 2 patients, both of whom were successfully treated with balloon dilatation of the stricture.

Gastroesophageal reflux. Gastroesophageal reflux was an extremely common early complication. Seven patients had significant symptoms for this condition, and 6 of those underwent Nissen fundoplication because of failure of medical therapy. Seizures occurred in 5 patients. None of these had a significant 


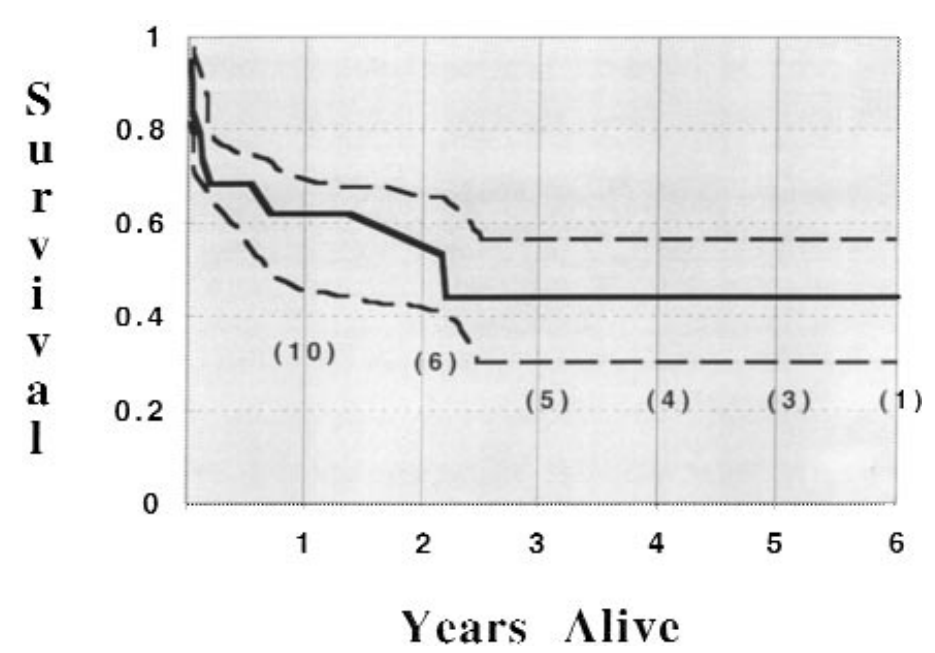

Fig 1. Actuarial survival for the 19 infants undergoing transplantation. There is an obvious significant early mortality rate, but a rather flat curve after 1 year. Seventy percent confidence limits are represented by the dashed lines above and below the solid line.

neurologic injury, and the presumed etiology was cyclosporine toxicity. All but one ultimately stopped receiving antieleptic medication without recurrence of the seizure disorder. One patient had atrial flutter during his early posttransplant course and began receiving procainamide. One patient had a phrenic nerve injury, resulting in prolonged need for mechanical ventilation.

Infections. Adenovirus infection occurred in 2 of the patients early after transplantation; this infection was directly responsible for one death and played a significant role in the death of the other patient. Acute respiratory distress syndrome developed in another patient in association with line sepsis approximately 5 months after transplantation. She ultimately required retransplantation and is currently doing well. Respiratory syncytial virus infection developed in one patient; she required supplemental oxygen during the infection but otherwise recovered uneventfully. The common cold and typical gastrointestinal viral infections have been tolerated well with a course that runs similar to that seen in the general population.

Rejection. As mentioned above, all infants undergo surveillance bronchoscopy and transbronchial biopsies in a protocol identical to that used for older children in our program. Transbronchial biopsies are also performed when indicated by a change in clinical status. For those patients surviving hospitalization, an average of $9 \pm 4$ biopsies have been performed during an average follow-up of 3 years. Two patients have had one histologically proven episode of A2 rejection each. Three other infants were treated for rejection empirically.
Late complications. To date, none of those surviving the hospitalization have had posttransplant neoplasms. At a mean follow-up interval of 3 years, 2 infants had bronchiolitis obliterans, both of whom died from this entity. The diagnosis of bronchiolitis obliterans is more difficult in small infants because they are not able to perform standard pulmonary function tests and thus cannot be assessed for bronchiolitis obliterans syndrome as defined by Cooper and colleagues. ${ }^{6}$ We used the information from infant pulmonary function tests performed as outlined above to create our own criteria for the diagnosis of bronchiolitis obliterans. When the ratio of specific flow at FRC to FRC per kilogram fell below $50 \%$ of predicted value in the absence of other pathologic processes, we believed the patient likely had bronchiolitis obliterans.

Survival. Overall survival for those undergoing transplantation is seen in Fig 1. Thirteen (68\%) of 19 survived hospitalization after the lung transplant. There were multiple causes for the 6 early deaths. Two infants died because of hepatic failure; one of these was caused by drug toxicity, and the other was related to an ischemic injury that occurred 1 week before the transplant. One patient had adenovirus infection, which resulted in respiratory failure. Two patients had severe graft failure early after transplantation and died because of other related complications. The patient undergoing transplantation for pulmonary hypertension and respiratory failure caused by congenital diaphragmatic hernia was receiving ECMO at the time of transplantation, and renal insufficiency was developing at the time of transplantation. He also (in retrospect) had some ongoing 

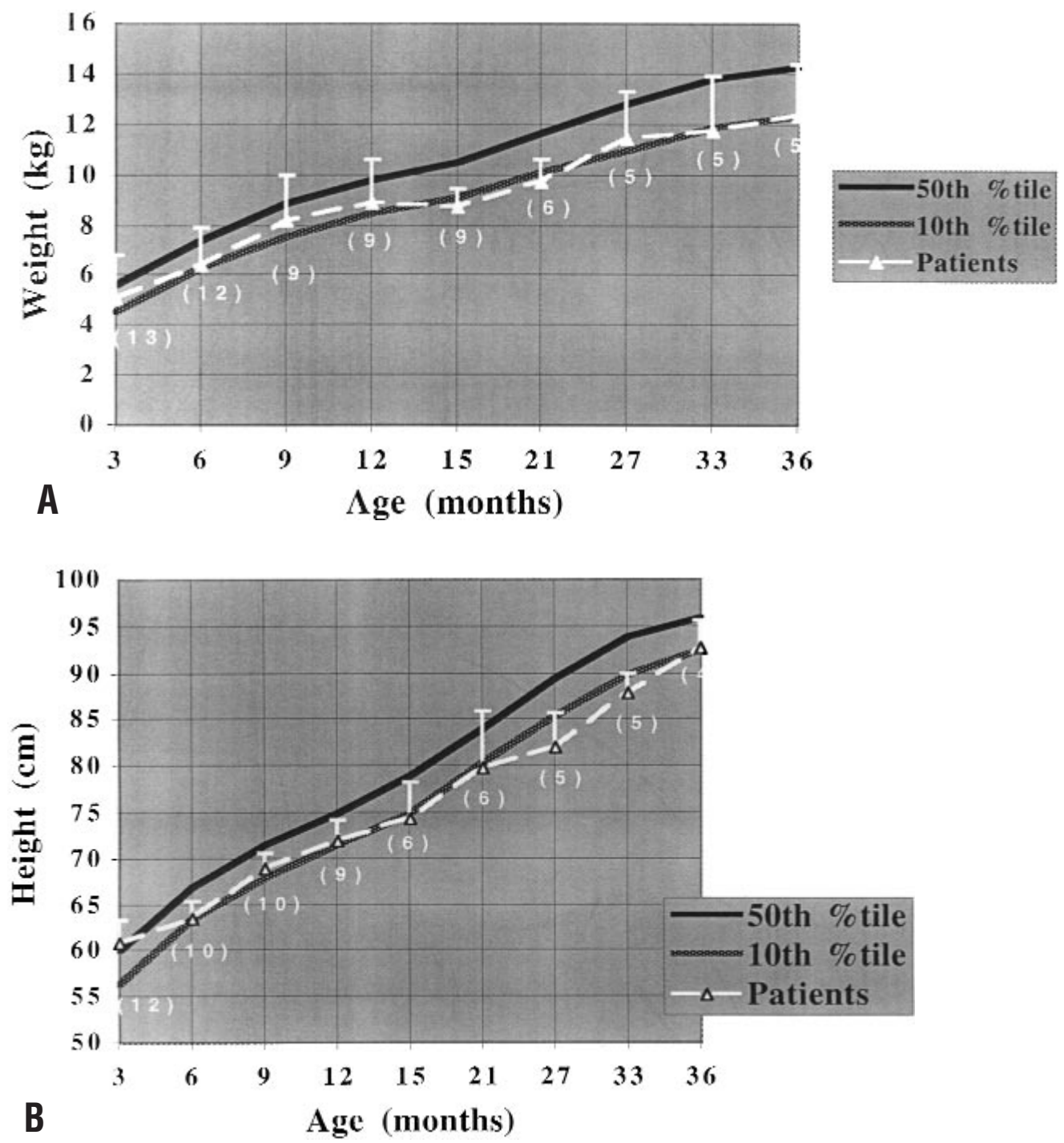

Fig 2. A, Growth in weight of the infants surviving the transplant hospitalization. Growth appears to track the 10th percentile of normal children through 3 years of life. B, Growth in height of the children surviving the transplant hospitalization. As with weight, height also closely tracks the 10th percentile.

sepsis at the time of transplantation. Multisystem organ failure developed after transplantation.

There have been 3 late deaths. Two of these were caused by bronchiolitis obliterans, as mentioned above. The other late death occurred 9 months after transplantation. This infant died suddenly while hospitalized for respiratory difficulties of unknown causes. An autopsy was not obtained, but it is presumed that her death was related to previously documented moderate tracheobronchomalacia involving her native proximal airways.

\section{Growth}

Somatic growth. Four of our patients have now survived for greater than 3 years after transplantation.
Their height and weight have steadily increased, albeit below the norm for their age. Both the weight and height are running between the 5 th and 10 th percentiles. The growth curves follow a relatively steady increase at this level (Fig 2, $A$ and $B$ ).

Lung growth. Growth of the transplanted lungs has been difficult to assess. As determined by chest radiography, the lungs appear bigger over time. Airway growth is suggested by the ability to tolerate the use of larger flexible bronchoscopes as the patients have grown older. In the absence of obstructive airway disease, FRC should remain a constant proportion of lung volume. Fig 3 shows a steady increase in FRC and fair- 


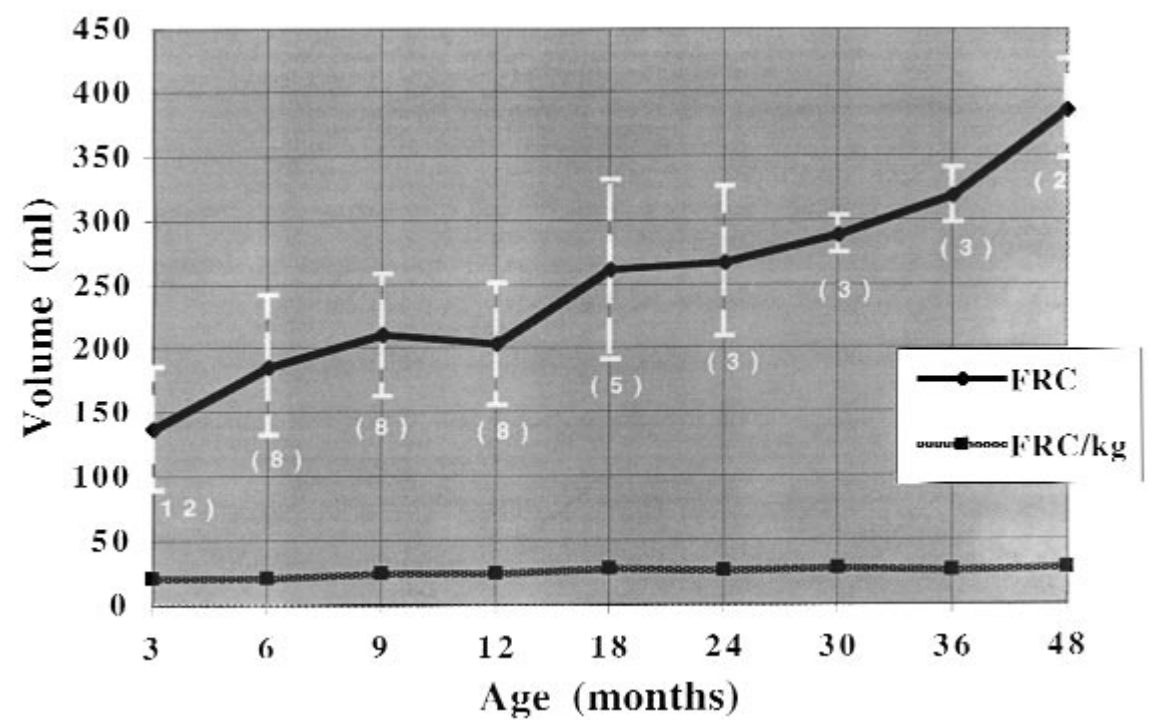

Fig 3. This shows a gradual increase in the FRC on the basis of infant pulmonary function tests. The tracing toward the bottom of the graph demonstrates that the FRC remains fairly constant when compared with the weight in kilograms. The normal FRC/kilogram ratio is approximately $30 \mathrm{~mL} / \mathrm{kg}$.

ly stable FRC/kilogram ratio over time for the patients in whom bronchiolitis obliterans did not develop.

\section{Discussion}

Our interest in lung transplantation in this age group was initially stimulated by a family in southern Missouri who had 2 prior infants die within weeks of birth because of respiratory failure. Both were born at term and were otherwise healthy. At postmortem examination, both infants had frothy pale-staining material in the distal air spaces. A diagnosis of surfactant protein-B deficiency was made on the basis of an open lung biopsy in the second infant before his death, thus linking the pathologic findings with the pathophysiologic process. ${ }^{7}$ By the time this mother was pregnant with her third child, our lung transplant program had been in place for 3 years. This child also had surfactant protein-B deficiency and was listed for lung transplantation. Unfortunately, he had a cerebral hemorrhage while awaiting donor organs. The genetic mutation for this autosomal recessive disorder has been identified on the second chromosome. The most common mutation observed to date results from a substitution and 2-bp insertion in exon 4 of the surfactant protein-B gene (121ins2). ${ }^{8}$ The diagnosis can now be made from a peripheral blood sample. Because surfactant protein B is expressed only in the lung, extrapulmonary organ function is unaffected by this mutation. Therefore these children generally are otherwise normal and theoretically should be excellent candidates for lung transplan- tation. Keeping these infants stable while awaiting organs has been challenging. In general, they have required a high-frequency oscillating ventilator with at least intermittent neuromuscular blockade.

Surfactant protein-B deficiency is now a fairly welldefined disease that has a universally fatal outcome. The other pulmonary parenchymal diseases for which we have attempted transplantation in infants are less well defined. In all cases we felt that there was absolutely no chance of recovery, and most infants were receiving significant support at the time of listing. For those with pulmonary hypertension, aggressive therapy to try to reverse this is obviously important. However, when this is caused by pulmonary vein stenosis, the likelihood of improvement is virtually zero. ${ }^{9}$ Therefore we would recommend early evaluation and listing for lung transplantation when this diagnosis is confirmed. We recommend early evaluation of term infants with unexplained respiratory distress. A peripheral blood sample for genetic testing for surfactant protein-B deficiency is a relatively simple start. Lacking that, lung biopsy is the next appropriate step, although a definitive diagnosis is frequently difficult. Infants with pulmonary hypertension are initially diagnosed by means of an echocardiogram but need a full cardiac catheterization to specifically rule out pulmonary vein stenosis and to characterize their response to pulmonary vasodilators.

When we embarked on lung transplantation for this group of patients, there were many unknowns poten- 
tially effecting the feasibility. Were there going to be donors available? Would the lungs grow? How would immunosuppressed small children tolerate routine infections of childhood? Would rejection be more of a problem, and how difficult would transbronchial biopsies be to establish the diagnosis? Given the incidence of bronchiolitis obliterans and its malignant course noted in adult lung transplant recipients, would there be any long-term survivors?

As to the issue of donor availability, each year there are approximately 100 cadaveric donors under the age of 1 year. For other age groups, $15 \%$ of organ donors will have lungs suitable for transplantation. ${ }^{10}$ If the same figures apply, 15 donors for infant recipients should be available annually in the United States. Given the rarity of diseases requiring transplantation in this age group, this should be sufficient. In fact, for calendar years 1994, 1995, and 1996, lungs were procured from 8,17 , and 14 cadaveric donors under the age of 1 year, respectively. ${ }^{10}$

Our data are suggestive, but not conclusive, of lung growth by alveolar multiplication. A definitive answer would require morphometric analysis of the lungs, which is not practical in the clinical setting. We have assumed that increases in FRC in the absence of pathologic processes represent increases in the numbers of alveoli. This assumption is supported in part by experimental work on immature rats receiving unilateral transplants. ${ }^{11}$ By using quantitative studies of histology, normal growth of the transplanted lungs occurred after 6 months, with increases in alveolar number and airway diameter both comparable with that found in control subjects not undergoing transplantation.

Our experience to date with what might be called the routine infections of childhood has been uneventful, thankfully. Virtually all the long-term survivors have had what appeared clinically to be a routine upper respiratory infection of viral etiology. None have become seriously ill because of these infections, and these infections ran their course much like they would in normal children.

Rejection has occurred much less frequently in this cohort of patients than in our general transplant experience, with only 2 documented episodes and 3 nondocumented episodes of rejection in 5 of the 13 survivors of the initial hospitalization. Their follow-up is an average of 3 years. This rejection incidence is much less than what we have seen in the older children in our series, in which $60 \%$ have had at least 1 episode of rejection in the first 6 months after transplantation. ${ }^{12}$ The transbronchial biopsy specimens obtained in these small infants are smaller than with the older children, and sampling error is clearly a possibility. It is possible that these infants may be relatively protected from rejection by virtue of undergoing transplantation at a time when the immune system is not yet fully matured.

Given the enormous investment in time involved with the care of these infants, a survival of less than $50 \%$ at 3 years after transplantation is disappointing. Most of these deaths have occurred in the first 6 months after transplantation, however, and the incidence of bronchiolitis obliterans has been $15 \%$ of those surviving more than 6 months. In fact, the survival for those discharged from the hospital was $77 \%$ over a mean follow-up period of 3 years. For a similar follow-up period, the incidence of bronchiolitis obliterans in our older patients is approximately $35 \%{ }^{12}$ This lower incidence may be a reflection of the apparent lower incidence of rejection seen in these infants. All this must be tempered by the realization that the diagnosis of bronchiolitis obliterans without the availability of standard pulmonary function tests is difficult. In a large series of lung transplants in adults, $52 \%$ of patients were diagnosed with bronchiolitis obliterans on the basis of pulmonary function tests alone and had no confirmatory histologic evidence. ${ }^{13}$ Although we have devised a means of arriving at the clinical diagnosis by using infant pulmonary function tests, this method is unproven until we have a greater number of patients. At any rate, we are cautiously optimistic about our intermediate-term survivors on the basis of the current data.

In summary, infant lung transplantation is a high-risk treatment modality for some newborns with otherwise lethal pulmonary diseases. It requires a significant investment of resources from the hospital and medical staff, particularly the neonatology service. The intermediate-term results are somewhat encouraging, especially for those surviving their initial hospitalization. Much more follow-up will be necessary to assess the overall effectiveness of this treatment for infants.

\section{REFERENCES}

1. Bridges ND, Mallory GB, Huddleston CB, Canter CE, Spray TL. Lung transplantation in infancy and early childhood. J Heart Lung Transplant 1996;15:895-902.

2. Sweet SC, Livne M, Mullins D, Mallory GB. Transbronchial biopsy in infants and toddlers [abstract]. Am Rev Respir Crit Care Med 1995;151:A95.

3. Gerhardt T, Hehre D, Bancalari E, Watson H. A simple method for measuring functional residual capacity by $\mathrm{N}_{2}$ washout in small animals and newborn infants. Pediatr Res 1985;19:1165-9.

4. Taussig LM, Landau LI, Godfrey S, Arad I. Determinants of forced experiatory flows in newborn infants. J Appl Physiol 1982;53:1220-7.

5. LeSouef PN, Castile R, Turner DJ, Motoyama E, Morgan WJ. Forced expiratory maneuvers. In: Stocks J, Sly PD, Tepper RS, 
Morgan WJ, editors. Infant respiratory function testing. New York: John Wiley and Sons, 1996. p. 387-9.

6. Cooper JD, Billingham M, Egan T, et al. A working formulation for the standardization of nomenclature and clinical staging of chronic dysfunction in lung allografts. J Heart Lung Transplant 1993;12:713-6.

7. Nogee LM, deMello DE, Dehner LP, Colten HR. Pulmonary surfactant protein B deficiency in congenital pulmonary alveolar proteinosis. N Engl J Med 1993;328:406-10.

8. Nogee LM, Gamier G, Dietz HC, et al. A mutation in the surfactant protein B gene responsible for fatal neonatal respiratory disease in multiple kindreds. J Clin Invest 1994;93:1860-3.

9. Mora BM, Balzer DT, Mendeloff EN, et al. Intermediate-term results of lung transplantation for pulmonary vein stenosis. Circulation 1998;98:1617.

10. Smith CM, White RR, Baker AS, Rosendale JD, editors. The U.S. Scientific Registry of Transplant Recipients and The Organ Procurement and Transplantation Network. 1997 Annual Report. Rockville, Md: US Department of Health and Human Services, Health Resources and Services Administration, Office of Special Programmer, Division of Transplantation; UNOS, Richmond, Va. p. 32-57.

11. Hislop AA, Odom NJ, McGregor CGA, Hawortb SG. Growth potential of the immature transplanted lung: an experimental study. J Thorac Cardiovasc Surg 1990;100:360-70.

12. Sweet SC, Spray TL, Huddleston CB, et al. Pediatric lung transplantation at St. Louis Children's Hospital 1990-1995. Am J Respir Crit Care Med 1997;155:1027-35.

13. Sundaresan S, Trulock EP, Mohanakumar T, Cooper JD, Patterson GA. Prevalence and outcome of bronchiolitis obliterans syndrome after lung transplantation. Ann Thorac Surg 1995;60:13417.

\section{Discussion}

Dr Thomas L. Spray (Philadelphia, Pa). It is a privilege for me to be able to discuss a paper from my former colleagues in St Louis on what I think is a very important topic, and it is quite gratifying to know that the St Louis program has continued to achieve excellent results in lung transplant even in very high-risk infants.

When we began the experience with infant lung transplant in St Louis, one of the great concerns was the potential for growth of the bronchial anastomoses. There was concern that a tracheal anastomosis, as in a double-lung transplant, might be better in terms of freedom from complications and potential for long-term growth. I was gratified to see that in longterm follow-up there have not been significant problems from the anastomoses in these very small infants.

I wonder if you could expand on your experience with these small patients and the monitoring that you performed to assess the growth of the bronchial, and also specifically the vascular, anastomoses with time. Do you do ventilation-perfusion testing in these patients routinely at follow-up, and then are angiograms done if there are ventilation-perfusion mismatches? We have seen in our own experience the occasional patient that has acquired pulmonary vein obstruction late after lung transplant in very small children.

Have any patients, in your experience, required dilation of the vascular anastomoses, either arterial or venous?
In a related question, I wonder if you could expand on the issue of lung growth. Have any of these children now become old enough to permit full pulmonary function testing or, even more importantly, exercise testing? I notice that you compared the index that you derived of functional residual capacity over body weight to that of normal infants. I wonder if normal infants maintain that growth over their entire lifetime. Does the fact that many of your patients required trimming of the lungs at the time of implantation affect the functional residual capacity of the lung because you are trimming off essentially the distal alveolar bed?

Are these children able to function normally in terms of social interactions and exercise now that they have become toddlers? There are a few patients now in your experience that are getting old enough to assess some of these issues.

In our own experience with infant lung transplant at the Children's Hospital of Philadelphia, we have had very similar results, but there has been a significant waiting mortality rate in infants who are listed for lung transplant. As in your experience, most patients required continuous ventilatory support or ECMO while waiting. I wonder if you have noted any change in the waiting time over the course of your experience? It is our impression that waiting times generally average greater than 1 month and seem to be increasing. Only 9 of 19 listed infants in our own experience actually received organs, but the average waiting time was about 35 days, and the time to death after listing was on average about 44 days. In your manuscript you describe the fact that there are not very many lung donors, and this was a major concern. I wonder if there will be enough donors for these children. If the mean time to death approximates the average waiting time, then this is a major problem for many of these infants. Should they be listed more immediately? Are we identifying these patients quickly enough to give them any chance of getting organs? Compared with our older patients, infants were significantly less likely than older children to survive on the list for 90 days or more, suggesting that waiting times are really very critical in these small infants.

I wonder if you are still using lobes from larger donors in infants? Only 2 patients in your experience had such use. Have the lobes in these children performed as well as total lungs in the cohort of patients that you described?

Our own experience of hospital survivorship of two thirds of the patients is quite similar to your own experience. We have seen very little rejection in these patients, but we have also seen a very high incidence of nonrespiratory nosocomial infections that are probably related to the severity of the illness at the time of transplant and the fact that these patients waited in the ICU with multiple invasive lines and then spent a long time there after transplantation. Have you noticed a difference in the infection rate in your very small infants compared with older patients who undergo transplantation?

This study clearly shows that the principles of lung transplantation can be applied across the entire range of patient age down to the neonatal and infant periods. The excellent results with lung transplantation and the comparability of results to 
transplantation in older children and adults is a significant achievement in the care of patients with complex respiratory disease, for which the authors are to be congratulated.

Dr Huddleston. Thank you, Dr Spray. We certainly appreciate the efforts that you put into initiating the program. Had you not left St Louis, your name would have been on this paper, of course.

That was a lot of questions. I think it's very difficult to measure some of these indices of growth. We have not routinely performed cardiac catheterization on the patients during their follow-up. They all do undergo ventilation-perfusion lung scanning.

If there is symmetric narrowing of both the vascular anastomoses, it will not be reflected in a standard perfusion scan because it is better for assessing unilaterality of the stenotic process if there is one. So far there has not been any clinical expression of stenosis in the pulmonary venous or pulmonary arterial anastomoses in any of the infants.

The only assessment that we have made of the bronchial anastomosis growth relates to the size of the bronchoscope used for the surveillance. In the children that are now over 4 years of age, we have advanced from the thin, or 2.2-mm bronchoscope, to a 3.4-mm diameter bronchoscope and then to a 4.7-mm bronchoscope without compromise of their airways. The bronchoscopy on the older children is done with them sedated but breathing on their own spontaneously. I recognize that is a very soft way to look at the size of the bronchus as it has grown over time, but at least there is the clinical impression on the basis of ease of passing the bronchoscope that in fact the bronchial anastomosis has grown. We have tried to look at this with computed tomography scans, which are also obtained on a routine basis annually for the patients when they come back for follow-up, but we have had a lot of difficulty with precise reconstruction consistently in every one of the patients to make an assessment of the size of the bronchus. None of the patients have had vascular dilatation.

We now have 2 patients who have the ability to perform standard pulmonary function tests. One of them is just over 4 years of age, and the other is 6 years old. The forced vital capacity for both of these patients is greater than $100 \%$ of predicted value. The forced expiratory velocity in 1 second for both of them is greater than $80 \%$ of predicted value. This is only 2 patients, but at least it looks fairly promising in terms of another indication of alveolar growth.

None of the patients have undergone exercise testing. Those that have reached the toddler stage appear to have normal peer-related activity tolerance, but again, that is a fairly soft call. They otherwise act like fairly normal children. The 6-year-old child is just finishing kindergarten and has performed more or less in the median of his class intellectually.
We have not really observed a change in the wait time. There has been a good deal of variability over the entire course of the program. The average list time to death of the 7 infants that died was 23 days. Although I did not elaborate, the ones that have had pulmonary vascular disease have had a higher waiting mortality rate than those with pulmonary parenchymal diseases. I think that the neonatologists have played a major role in really establishing a way to take care of these children from a respiratory standpoint when it is a parenchymal disease process, and I think it is much more difficult when it is a pulmonary vascular process that is taking place, in terms of keeping them alive.

Your program in Philadelphia has tended to be more weighted toward pulmonary vascular disease problems, and I would not be at all surprised if that has perhaps contributed to a higher number of deaths on the waiting list in the infant group.

We have only performed lobar transplants in 2 infants. I think it is a little difficult to say how they perform relative to the other group in general, and I could not make any concrete statements about that.

It is a big problem when they have to wait this long in the intensive care unit because of all the issues that you raised (ie, nosocomial infections and vascular access for TPN when necessary). The children that received high-frequency oscillating ventilator treatment for a long time before they were transplanted have had a tremendous amount of edema related to the high central venous pressures that constant high ventilatory pressure requires, and that has led to a considerable amount of morbidity before the transplant as well.

I hope that covers most of the questions.

Dr Thomas M. Egan (Chapel Hill, NC). Congratulations on very good results in a tremendously difficult population of patients. It is one thing to offer a teenager a $50 \%$ or $60 \%$ shot at 5 years' survival, which is what we do with transplantation for cystic fibrosis and other types of lung diseases in that age group. How many parents have turned down the opportunity for transplant given the actuarial survival opportunities, which are clearly less than the adult population, and really, at this stage of the game, with the knowledge that the actuarial probability of survival to adulthood must be very low?

Dr Huddleston. That is an excellent point. Before we accept a patient in transfer from another institution to ours for consideration for transplantation in any group, but particularly the infant group, we have a telephone conversation with the family and lay out the odds specifically to them for survival. As it turns out, a fairly low number refuse or turn down the opportunity. I could not tell you off the top of my head what it is, but it is certainly well under $25 \%$. Most of them will proceed to go forward with the procedure. 